A - Research concept and design

B - Collection and/or assembly of data

C - Data analysis and interpretation

D - Writing the article

E - Critical revision of the article

F - Final approval of article

Received: 2021-09-18 Accepted: 2022-02-02 Published: 2022-02-03

\section{The effect of concurrent endurance-resistance training on serum testosterone levels, body composition, muscular strength and international index of erectile function in older men}

\author{
Mohammad Parastesh *1,A-F (D), Abbas Saremi ${ }^{1, B-C}$ (D), \\ Yaghoob Hashemi ${ }^{2, B, D, F}$ (D), Sajad Ramezani ${ }^{1, D}$ (D), \\ Negar Shavandi ${ }^{3, C-D}$ \\ ${ }^{1}$ Department of Sport Physiology, Faculty of Sport Sciences, Arak University, \\ Arak, Iran \\ ${ }^{2}$ Department of Sport Physiology, Faculty of Sport Sciences, Shiraz University, \\ Shiraz, Iran \\ ${ }^{3}$ Department of Biology, Faculty of Sciences, York University, Toronto, \\ Canada
}

*Correspondence: Mohammad Parastesh, Department of Sport Physiology, Faculty of Sport Sciences, Arak University, Arak, Iran; email: M-Parastesh@Araku.ac.ir

\title{
Abstract
}

Introduction: The aim of this study was to evaluate the effect of 12 week concurrent endurance-resistance training on serum testosterone levels and sexual function indices in men over 50 years of age.

Material and methods: In this quasi-experimental study, the statistical sample consisted of 29 men with average weight of $81.1 \pm 6.7 \mathrm{~kg}$ and body mass index of $26.4 \pm 1.4 \mathrm{~kg} / \mathrm{m}^{2}$, randomly divided into two control group $(\mathrm{n}=12)$ and training group $(\mathrm{n}=17)$. The training group performed concurrent training (endurance-resistance) for 12 weeks. Serum testosterone levels, cardiopulmonary endurance $\left(\mathrm{VO}_{2} \max \right)$, muscle strength and body composition were measured before and after training. Data were analyzed using covariance analysis (ANCOVA) $(p<0.05)$.

Results: Concurrent training in the training group significantly increased serum testosterone levels compared to the control group $(p=0.001)$. Concurrent training also increased sexual function in the areas of orgasmic performance $(p=0.010)$ and total score $(p=0.004)$ in the concurrent training group compared to the control group. Training significantly decreased fat mass $(p=0.046)$ and the ratio of waist to hip circumference $(p=0.024)$ also significantly increased $\mathrm{VO}_{2} \max (\mathrm{p}=0.001)$, mean relative muscle strength $(\mathrm{p}=0.001)$ and lean body mass $(\mathrm{p}=0.001)$ in the training group compared to the control group.

Conclusions: In general, based on our findings, it seems that training along with increasing serum testosterone levels increases sexual function in the areas of orgasm function and the total score in men over 50 years.

Keywords: testosterone, concurrent training, elderly, erectile function

\section{Introduction}

Erection is a complicated phenomenon resulting from a harmonic and delicate balance of textural, neural, and vascular systems. This phenomenon includes vascular extension, Trabecular smooth muscle looseness, and activation of Corporeal Veno-Occlusive
Mechanism [1]. Erectile dysfunction is defined as a failure in completing sustainable erection, preserving an erection and reaching satisfactory sexual performance [2]. Evidence confirmed erectile dysfunction as an early manifestation of cardiovascular diseases. Erectile dysfunction is not only a living quality issue but also it's a potential sign of cardiovascular diseases [3]. In 
addition, studies have shown that erectile dysfunction can have a significant impact on the physical and mental health of patients and their spouses [4]. Epidemiologic data showed prevalence and high rate of erectile dysfunction worldwide. The Massachusetts Male Aging Study (MMAS) reported 52\% of the total prevalence of erectile dysfunction among 40 to 70 males in the Boston area also, the particular prevalence for low, mid, and high erectile dysfunctions was $17.2 \%, 25.2 \%$, and $9.6 \%$ respectively [5]. Emergence rate of erectile dysfunction (new cases per year among 1000 males) in a long-span study of data study in The Massachusetts Male Aging Study (MMAS) [6] and a study in the Netherlands was 19.2 (average follow-up was 4.2 per year) [7]. Risk factors of erectile dysfunction with both vascular coroner diseases corrective and dis-corrective risk factors (for example; obesity, sweet diabetes, dyslipidemia, metabolic syndrome, smoking, and lack of exercise) are common [8]. A meta-analysis in 2020 pieces of evidence showed that erectile dysfunction has a significant and independent relationship with not only cardiovascular diseases risk rate but also with coronary artery disease, stroke, and other mortality factors [9].

Also, one of the most important reasons for erectile dysfunction in males is androgen hormone level decrease in particular testosterone hormone decline. According to net studies, it was confirmed that as males' ages the testosterone level decrease. Androgen decline in males is accompanied by a persistent, ongoing, and progressive aging process [10].

Calzo et al. [3] in a study showed that among sexually active men $11.3 \%$ have mild erectile dysfunction and $2.9 \%$ have moderate erectile dysfunction with various demographic (age, marital status) metabolic (body mass index, waist circumference, history of diabetes, high blood pressure, high cholesterol) and mental health (depression, anxiety, taking antidepressants and sedatives) factors associated. The study also found that erectile dysfunction was common in a large sample of young American men and was directly related to mental health [3]. After the fourth decade of life, free testosterone levels decrease by 1 to 2 percent per year, although total testosterone decrease follows the same path but with a lower rate $(0.4 \%$ per year $)$ which is related to hemoglobin level increase connected to sex hormones. Based on total testosterone, $20 \%$ of above 60 years old males, $30 \%$ of 70 years old males, and $50 \%$ of over 80 years old males suffer from lack of androgen [11]. Decreased production and function of androgens can lead to decreased muscle mass and strength, decreased occasional morning erections, decreased libido and sexual function, increased fat mass, erectile dysfunction, sweating, insomnia, irritability, and depression [12].
On the other hand, aging is accompanied by a gradual decrease in aerobic capacity, muscle mass, and strength. These decreases are accompanied by an increase in obesity, type 2 diabetes, cardiovascular disease, prostates cancer, and sexual function decrease [13]. At the same time, a combination of resistance training and endurance training due to their positive influence on concurrent preserve or increase in skeletal and muscle resistance and mass and aerial preparedness is suggested significantly [14]. Current instructions of American College of Sports Medicine [15] indicated that endurance training must be performed with intensity lower than $60 \%$ of maximal oxygen consumption $\left(\leq 60 \% \mathrm{VO}_{2} \max \right)$ and resistance training must be performed with intensity lower than $60 \%$ of one-repetition maximum (1-RM) to improve muscular, neural, cardiovascular systems functions in older male.

Studies indicate that exercises training led to serum testosterone levels increase among adult males [16]. Although, it seemed that there is a lack of research focusing on training and sexual performance following testosterone increase. Also, there are lots of contradictions about training and exercise methods results. Thus, this research aims to study concurrent endurance-resistance training influence on serum testosterone levels and sexual function of over 50 years old males to evaluate training method usage in prevention from aging deficits through serum testosterone levels control and sexual function.

\section{Materials and methods}

The current study was a semi-experiment research in form of two groups with a pre-test and post-test. Amongst over 50 years old male employees of arak petrochemical company, 33 male volunteered to participate in this study. The inclusion criteria were: age between 50 to 59 years old, no background of cardio-vascular diseases, no background of diabetic diseases, no participation in regular training in recent 60 months, no background of blood pressure higher than 160/95 $\mathrm{mmHg}$, no background of smoking, no background of using supplements, no background of using drugs declining blood sugar, lack of blood pressure and blood fat control in two recent months. After initial evaluation 33 male volunteers were selected by specific criteria and randomly divided into control $(\mathrm{n}=14)$ and concurrent training $(n=19)$ groups. Two participants were dropped out due to non-regular participation in concurrent training and also 2 people from the control group were dropped out due to lack of participation in post-test in the final stage of research. Finally, this research was completed by 29 participants (Fig. 1). 


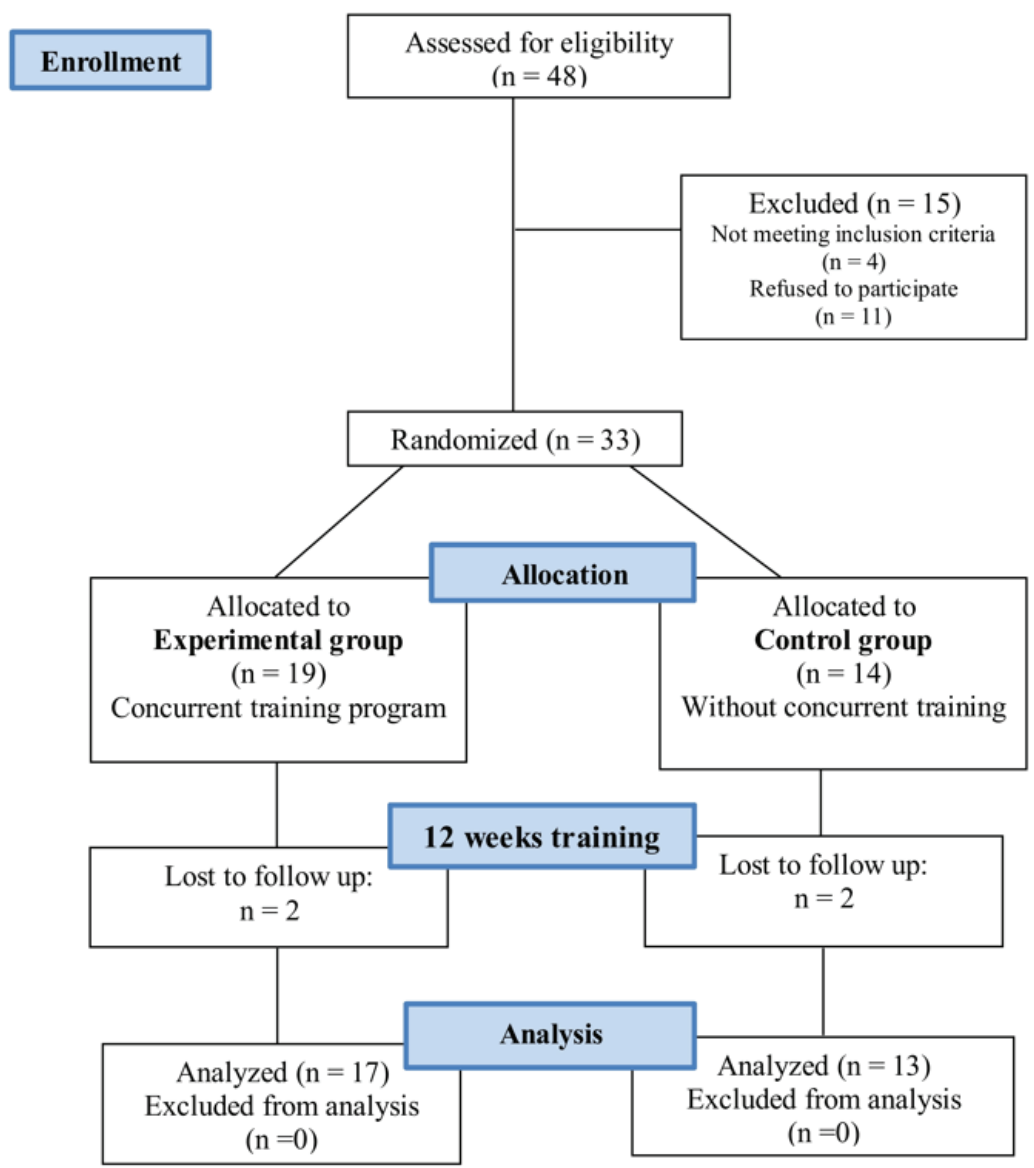

Fig. 1. CONSORT flow diagram of participants through the intervention

Sample volume was done based on previous studies in this field and then based on G Power software outcomes, so that effect size volume was 1.1, type one error size (alpha 0.5), and type two error size volume (beta 0.1) were included. A week before the training program begins, all participants fill out content forms to participate in research and also they fill out food questionnaire for 3 days including one holiday, and then, in case of necessity, nutrition experts deliver the required food advice for the training protocol period. The weight was measured by Winsor digital scale (Germany) with $0.1 \mathrm{~kg}$ preciseness and height was measured by Yagami height measure (Japan) and body mass index (BMI) was calculated. Skin folds were measured by Seahan caliper (South Korea) and fat percentage was measured by 7 points skin wave measurement (hip, chest, underarm, under shoulder, upper bowel, triceps, and abdomens), and body weight computation (Siri formula) and its assignment in Jackson and Pollack formula were determined. Also waist-to-hip ratio (WHR) was calculated using abdomen circumference divided $(\mathrm{cm})$ by hip circumference $(\mathrm{cm})$ [15]. The University Arak Medical School research ethics committee approved this study plan (IR-Arakmu.rec.1398.145).

\section{Biochemical measurements}

The first blood sampling from the arm vein of the participant was collected at 8 am in the fasting state and the second blood sampling was collected at the same time 48 hours after the last training session. Blood samples were transferred into the laboratory and blood serum was separated by centrifuge (for $5 \mathrm{~min}$ by 3000 $\mathrm{rpm})$. They were collected in microtubes and frozen at $-20^{\circ} \mathrm{C}$ until the time of analysis. Serum testosterone level was measured using Cobas E411 and applying electrochemical-luminance new technology (ECL) made in Germany and using the set special kit with a dynamic range of $0.1-17 \mathrm{ng} / \mathrm{mL}$ and sensitivity of $0.022 \mathrm{ng} / \mathrm{mL}$.

\section{Sexual function evaluation}

Sexual function was evaluated by the International Index of Erectile Function (IIEF) to measure sexual desire, sexual activity, and sexual satisfaction. This questionnaire include 15 questions divided into 5 parts: erectile function (Questions 15, 1-5), orgasm function (Questions 9 and 10), sexual desire (Questions 11 and 12), marital satisfaction (intercourse) (Questions $12,6-8)$ and total satisfaction (Questions 13, 14, 17) 
[17]. Each question of the questionnaire has 5 scores and scales. The questions scores in pre-test and post-test were computed and reported based on sexual function disorders and questionnaire total score. The reliability of the IIEF was studied by the alpha Cronbach coefficient. Also, the total scale had 0.93 internal analogies.

\section{The concurrent endurance-resistance training program}

Participants performed a concurrent endurance-resistance training program 3 times per week for 12 weeks. Endurance training lasted for 40 minutes and started with a $40 \%$ target heart rate (THR) and reached $80 \%$ THR in the final sessions. The criterion for designing the endurance program was heart rate. To measure the target heart rate, first, the subjects 'resting heart rate was measured and then the target subjects' heart rate was calculated using the Karvonen formula. Polar model $\mathrm{H}_{6}$ monitors were used to adjust the intensity of exercise. The participants were also taught how to measure heart rate and each person was given a heart rate range during endurance training. They were asked to perform their exercises within the specified heart rate range. Progressive resistance training started with an intensity of 50\% of one-repetition maximum (1RM) and progressively increased to $80 \%$ of $1 \mathrm{RM}$ by the end of the training period. The amount of $1 \mathrm{RM}$ was calculated using the Berziski formula [15]:

1RM $(\mathbf{K g})=$ replaced weight $(\mathrm{kg})$

$\div(1.0278-(0.0278 \times$ repetitions till fatigue $))$.

Resistance exercises included 4 upper body movements (press with the machine, head with the machine, and forearm with the machine and armpits with the machine) and 4 lower-torso movements (press with the machine, back with the machine). The load increased by $10 \%$ every two weeks. Each of the 8 movements was performed in 3 sets and 6 to 8 repetitions in each set, with a 30 -second break between each set and a 2-minute break between each movement (Tab. 1).

The sessions were carried out in small 2-4 people groups directly supervised by a sports physiologist (researcher) [15].
Also, to compute max oxygen consumption (aerobic capacity), it was used 1 mile jogging with a stable speed test with the George et al formula [18].

$\mathbf{V O}_{2} \mathbf{m a x}(\mathrm{ml} / \mathbf{k g} / \mathbf{m i n})=108.844-0.1636$ (weight $\mathrm{kg})-0.1636$ (time to $\mathrm{min}$ ) -0.1636 (heart rate at the end of 1 mile jogging per min).

\section{Statistical analysis}

Results were presented as average and standard deviation for current samples. To ensure about data normal distributions Shapiro-Wilk test was used. Independent $t$-test was used for comparison of post-test results, in which pre-test showed significant differences among research groups. ANCOVA was used for the post-test comparison of the results in which pretest values were used as a covariate insignificant level $\mathrm{p} \leq 0.05$. All statistical computations were performed using SPSS version 22 statistical software and graph pad prism version 8 .

\section{Results}

The mean age and height of the control group and the concurrent training group were $53.6 \pm 2.15$ years old, $173.4 \pm 7.46 \mathrm{~cm}$, and $52.7 \pm 2.2,174.4 \pm 0.04 \mathrm{~cm}$ respectively. All variables of the present study had a normal distribution $(p \leq 0.05)$. The results of independent t-test showed significant difference between the studied groups in lean mass, WHR, percentage of fat mass and maximum oxygen consumption in post-test (Tab. 2).

ANCOVA results showed that there was significant differences in machine bench press, flat bench cable flyer, dumbbell one arm shoulder press, triceps with dumbbell, calf with machine, bicep tight with the machine, seated leg curl, hyperextension, flat, average relative strength between the control group and the concurrent training group in the post-test (Tab. 3).

In addition, the results of analysis of covariance (ANCOVA) showed that there was a significant difference in the variable of serum testosterone level between the control group and the concurrent training group in the post-test $(\mathrm{F}=0.23, \mathrm{p}=0.001)$ (Fig.2).

Tab. 1. Progressive concurrent endurance-resistance training program during 12 weeks of training

\begin{tabular}{lcccc}
\hline Weeks & Week 1-3 & Week 3-6 & Week 6-9 & Week 9-12 \\
\hline Resistance training & $40-45 \% 1 \mathrm{RM}$ & $45-50 \% 1 \mathrm{RM}$ & $50-55 \% 1 \mathrm{RM}$ & $55-60 \% 1 \mathrm{RM}$ \\
Endurance training & $40-50 \% \mathrm{THR}$ & $50-60 \% \mathrm{THR}$ & $60-70 \% \mathrm{THR}$ & $70-80 \% \mathrm{THR}$ \\
\hline
\end{tabular}

1RM - one-repetition maximum; THR - target heart rate. 
Tab. 2. Comparison of $\mathrm{VO}_{2} \max$ and body composition characteristics in the studied groups

\begin{tabular}{|c|c|c|c|c|}
\hline \multirow{3}{*}{ Variables } & \multirow{3}{*}{ Stages } & \multicolumn{2}{|c|}{ Groups } & \multirow{3}{*}{$\mathrm{p}$} \\
\hline & & Control & Concurrent Training & \\
\hline & & Mean \pm SD & Mean \pm SD & \\
\hline \multirow{2}{*}{ Weight (kg) } & Pre-test & $80.7 \pm 6.96$ & $79.5 \pm 9.96$ & 0.799 \\
\hline & Post-test & $80.10 \pm 5.63$ & $80.6 \pm 01.06$ & 0.873 \\
\hline \multirow{2}{*}{ Body Fat Mass (\%) } & Pre-test & $29.2 \pm 8.86$ & $29.3 \pm 01.06$ & 0.859 \\
\hline & Post-test & $30.3 \pm 4.47$ & $28.2 \pm 3.9$ & $0.046^{*}$ \\
\hline \multirow{2}{*}{ Lean Body Mass (kg) } & Pre-test & $56.4 \pm 4.71$ & $55.3 \pm 6.36$ & 0.607 \\
\hline & Post-test & $55.3 \pm 6.38$ & $58.35 \pm 1.9$ & $0.048 *$ \\
\hline \multirow{2}{*}{ Body Mass Index $\left(\mathrm{kg} / \mathrm{m}^{2}\right)$} & Pre-test & $26.1 \pm 7.12$ & $26.1 \pm 2.63$ & 0.361 \\
\hline & Post-test & $26.1 \pm 6.9$ & $26.1 \pm 2.63$ & 0.580 \\
\hline \multirow{2}{*}{ Waist-Hip Ratio (cm) } & Pre-test & $1.0 \pm 01.03$ & $1.0 \pm 0.04$ & 0.350 \\
\hline & Post-test & $1.0 \pm 01.05$ & $0.97 \pm 0.03$ & $0.02 *$ \\
\hline \multirow{2}{*}{$\mathrm{VO}_{2} \max (\mathrm{ml} / \mathrm{kg} / \mathrm{min})$} & Pre-test & $44.2 \pm 11.48$ & $45.3 \pm 99.06$ & 0.081 \\
\hline & Post-test & $44.2 \pm 20.35$ & $48.2 \pm 33.41$ & $0.001 *$ \\
\hline
\end{tabular}

*Between groups comparison by independent t-test with significant at the $\mathrm{p} \leq 0.05$ level (2-tailed).

Tab. 3. Comparison of muscle strength in different muscle groups in the studied groups

\begin{tabular}{|c|c|c|c|c|}
\hline \multirow{3}{*}{ Variables } & \multirow{3}{*}{ Stages } & \multicolumn{2}{|c|}{ Groups } & \multirow[b]{3}{*}{$\mathrm{p}$} \\
\hline & & Control & Concurrent Training & \\
\hline & & Mean $\pm \mathrm{SD}$ & Mean $\pm \mathrm{SD}$ & \\
\hline \multirow{2}{*}{ Machine bench press (lb) } & Pre-test & $10.07 \pm 0.5$ & $15.45 \pm 7.5$ & 0.004 \\
\hline & Post-test & $10.06 \pm 0.4$ & $25.37 \pm 4.7$ & $0.001 *$ \\
\hline \multirow{2}{*}{ Flat Bench Cable Fly (kg) } & Pre-test & $10.12 \pm 0.50$ & $12.99 \pm 2.62$ & 0.022 \\
\hline & Post-test & $10.15 \pm 0.16$ & $22.62 \pm 2.23$ & $0.001 *$ \\
\hline \multirow{2}{*}{ Dumbbell Shoulder Press (kg) } & Pre-test & $8.75 \pm 1.68$ & $10.11 \pm 1.96$ & 0.009 \\
\hline & Post-test & $8.90 \pm 1.71$ & $18.12 \pm 1.96$ & $0.001 *$ \\
\hline \multirow{2}{*}{ Triceps with dumbbell (kg) } & Pre-test & $11.87 \pm 6.68$ & $12.76 \pm 2.29$ & 0.026 \\
\hline & Post-test & $11.52 \pm 6.2$ & $15.11 \pm 2.1$ & $0.001 *$ \\
\hline \multirow{2}{*}{ Calf with Machine (kg) } & Pre-test & $20.88 \pm 6.45$ & $25.52 \pm 2.93$ & 0.001 \\
\hline & Post-test & $20.10 \pm 5.1$ & $36.43 \pm 1.91$ & $0.001 *$ \\
\hline \multirow{2}{*}{ Tight with Machine (kg) } & Pre-test & $11.60 \pm 9.37$ & $13.12 \pm 1.69$ & 0.024 \\
\hline & Post-test & $12.11 \pm 8.21$ & $24.12 \pm 1.12$ & $0.001 *$ \\
\hline \multirow{2}{*}{ Seated leg curl (kg) } & Pre-test & $10.1 \pm 1.69$ & $13.66 \pm 2.60$ & 0.001 \\
\hline & Post-test & $11.1 \pm 1.51$ & $24.16 \pm 1.17$ & $0.001 *$ \\
\hline \multirow{2}{*}{ Back Extension Machine (kg) } & Pre-test & $43.60 \pm 2.75$ & $46.17 \pm 5.91$ & 0.001 \\
\hline & Post-test & $44.12 \pm 2.11$ & $27.11 \pm 4.80$ & $0.001 *$ \\
\hline \multirow{2}{*}{ Abdominal Crunch Machine (kg) } & Pre-test & $42.51 \pm 2.78$ & $45.13 \pm 4.85$ & 0.001 \\
\hline & Post-test & $43.12 \pm 3.12$ & $56.10 \pm 2.95$ & $0.001 *$ \\
\hline \multirow{2}{*}{ Relative Strength (kg/body mass) } & Pre-test & $0.242 \pm 0.016$ & $0.273 \pm 0.057$ & 0.001 \\
\hline & Post-test & $0.256 \pm 0.023$ & $0.452 \pm 0.047$ & $0.001 *$ \\
\hline
\end{tabular}

*Between groups comparison by in post-test due to significant differences of pre-test by ANCOVA, pre-test values assigned as covariates with significant at the $\mathrm{p} \leq 0.05$ level (2-tailed). 


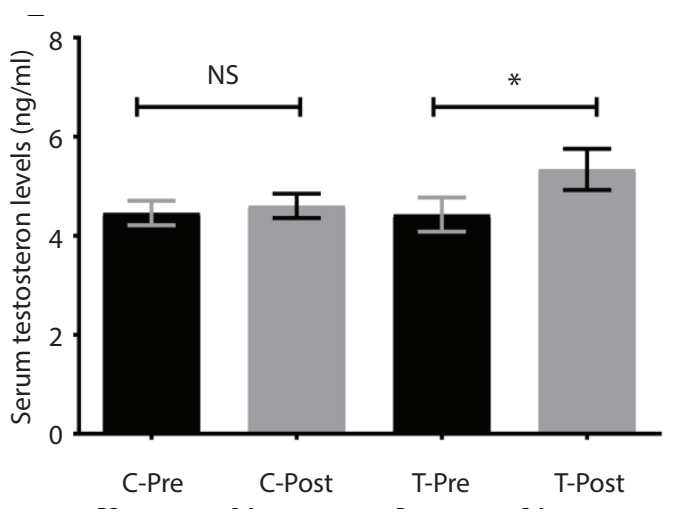

Fig. 2. Serum testosterone levels in the study groups

C-Pre $=$ pre-test of control group, C-post $=$ post-test of control group, T-Pre $=$ pre-test of concurrent training group, T-post $=$ post-test of concurrent training group. * Existence of significant difference, NS: no significant difference, intergroup comparison by analysis of covariance (ANCOVA) and Bonferroni post hoc test at the significant level of $p \leq 0.05$. Values are expressed as mean \pm mean standard error.

Also, in case of various aspects of sexual function like erectile function, orgasm function, sexual desire, marital satisfaction, total satisfaction and total scores of ANCOVA test results showed that there were significant differences between orgasm function, and total scores between the control group and the concurrent training group in the post-test. There were no significant differences between erectile function, marital satisfaction, total satisfaction and sexual desire between the control group and the concurrent training group in the post-test (Tab. 4).

\section{Discussion}

This research aimed to study the influence of concurrent resistance-endurance training on serum testosterone levels and sexual function of males above 50 years old. Research results showed that 12 weeks of training led to a significant increase of cardiopulmonary capacity, muscular resistance and serum testosterone levels increase following sexual function indices improvement (especially in orgasm function and total score aspects) among participants from the experiment group compared to the control group.

One of the findings was that training group testosterone hormone level increased compared to the control group after 12 weeks of concurrent resistance-endurance training. Due to a lack of research about the study of concurrent resistance-endurance training, the current study is faced with restrictions. Other researchers studied resistance training, endurance training, complex resistance, and endurance training. On the other hand, previous researches results about the influence of training exercise on testosterone sexual hormone level were different. The highest density of serum testosterone levels were observed after heavy endurance training with short repetitive rests and high metabolic stress $[19,20]$. Short-time endurance training increases

Tab. 4. Comparison of various aspects of sexual function in studied groups

\begin{tabular}{|c|c|c|c|c|}
\hline \multirow{3}{*}{ Variables } & \multirow{3}{*}{ Stages } & \multicolumn{2}{|c|}{ Groups } & \multirow{3}{*}{$\mathrm{p}$} \\
\hline & & Control & Concurrent Training & \\
\hline & & Mean \pm SD & Mean \pm SD & \\
\hline \multirow{2}{*}{ Erectile Function } & Pre-test & $27.16 \pm 2.12$ & $23.50 \pm 3.5$ & 0.006 \\
\hline & Post-test & $26.32 \pm 0.93$ & $26.08 \pm 0.93$ & 0.870 \\
\hline \multirow{2}{*}{ Orgasm Function } & Pre-test & $9.50 \pm 0.79$ & $7.75 \pm 0.86$ & 0.001 \\
\hline & Post-test & $9.14 \pm 0.20$ & $10.10 \pm 0.21$ & $0.01 *$ \\
\hline \multirow{2}{*}{ Sexual Desire } & Pre-test & $6.83 \pm 1.40$ & $5.75 \pm 1.54$ & 0.086 \\
\hline & Post-test & $6.31 \pm 0.09$ & $6.10 \pm 0.1$ & 0.158 \\
\hline \multirow{2}{*}{ Marital Satisfaction } & Pre-test & $12.50 \pm 1.1$ & $9.50 \pm 1.50$ & 0.001 \\
\hline & Post-test & $11.38 \pm 0.38$ & $11.36 \pm 0.40$ & 0.968 \\
\hline \multirow{2}{*}{ Total Satisfaction } & Pre-test & $9.0 \pm 0.60$ & $8.25 \pm 0.45$ & 0.002 \\
\hline & Post-test & $8.57 \pm 0.16$ & $8.59 \pm 0.15$ & 0.959 \\
\hline \multirow{2}{*}{ Total Scores } & Pre-test & $65 \pm 1.70$ & $54.75 \pm 5.78$ & 0.001 \\
\hline & Post-test & $59.21 \pm 1.1$ & $64.78 \pm 1.2$ & $0.004 *$ \\
\hline
\end{tabular}

*Between groups comparison by in post-test due to significant differences of pre-test by ANCOVA, pre-test values assigned as covariates with significant at the $\mathrm{p} \leq 0.05$ level (2-tailed). 
anabolic hormones but severe and longtime endurance training might decrease testosterone density [21].

Rashidi et al. [22] suggested that endurance training has a positive influence on testosterone values. Also, previous research showed a significant increase in testosterone after concurrent endurance and resistance training $[23,24]$. Inconsistent with current study findings, Cadore et al. [25] observed a significant decrease in testosterone level among concurrent endurance and resistance training groups. On the other hand, Sheikholeslami et al. [26] observed no change in testosterone value after concurrent training. It seemed that different physical wellbeing of the participants or lack of training volume and intensity in previous studies might result in lack of significant increase in testosterone hormone. The influential factors on testosterone hormone response rate to training exercise are intensity, volume and time of trainings, rests and intervals between training sets, active muscular group, and individual's various types of training activity [27].

Physical training's influence on testosterone levels might be different based on age of the participants. For example, in comparison to adolescents, adult males showed incremental reaction to testosterone following an endurance training session [28]. Other studies suggested that lower levels of testosterone in response to the physical training of males above 50yrs are related to a kind of hypogonadism of old males [29]. Testosterone value increase in the current study might be related to some mechanisms proposed by researchers including testicles blood circulation increase, sympathetic neural system activation, lactate density increase, luteinizing hormone density increase, plasma volume changes, and testosterone omission decrease from blood circulation, testicles gland secretion increase and testosterone secretion in response to vascular extensions [30].

Testosterone secretion from testicles occurs when Leydig cells are stimulated by lutein hormone through the anterior pituitary. Secreted testosterone value partially had a direct relationship with lutein hormone value. Secreted testosterone by testicles in response to luteinizing hormone has bidirectional influence with lutein hormone through anterior pituitary. The highest portion of this restriction is caused by the direct influence of testosterone on the hypothalamus and the gonadotropin hormone decrease. This issue led to an appropriate decline of lutein hormone secretion through the anterior pituitary and decrease lutein hormone secretion and testosterone secretion from testicles. Whenever testosterone secretion exceeds the upper limit, this function causes negative self-regulation influence through the hypothalamus and anterior pituitary gland and decreases testosterone secretion level to appropriate level [31].
The other finding of current research showed that concurrent resistance-endurance training caused sexual function improvement among males over 50 yrs. This finding is consistent with Traen et al. [32] who suggested that there are direct and positive correlations between regular physical activity and sexual function. Also, current results are consistent with Karataza et al. [33] who pointed to the positive influence of physical activity on sexual function. Eidelberg et al. [34] also showed in a study that erectile dysfunction can be multifactorial and that exercise can manage many risk factors by improving endothelial function and improving quality of life [34]. It seemed that doing physical exercise caused testosterone hormone increase and led to sexual function improvement in males. According to previous studies this might lead to stress and anxiety decrease, mood traits, and mental condition improvements of individuals that increase sexual pleasure and improve sexual function. On the other hand, physical wellbeing promotion and good feeling about the body after physical training improve sexual function. On the other hand, blood circulation increase caused by training might improve erectile function and increase male penis vascular oxide nitric and also increase gonadotropins stimulate sperms and inspire erection in males [35].

The other finding of the current study was the $\mathrm{VO}_{2}$ max increase of the training group compared to control group after 12 weeks of concurrent resistance-endurance training. Consistent with current study results, Garcia et al. [36] suggested that 3 months of concurrent intensive training increase aerial function, muscular relative strength, and balance among males over $65 y$ rs. Also, Rakabdarkolaee et al. [37] studied the influence of 8 weeks of concurrent training on aerobic capacity in prostate cancer patients and observed that this training period might improve the $\mathrm{VO}_{2}$ max and body compound of these patients.

Since the current study was conducted among among inactive individuals, they showed lower $\mathrm{VO}_{2} \max$ than active people in the initial stage of training. The $\mathrm{VO}_{2-}$ max increase in experiment group resulting from training among these individuals was expected. Along with current study findings, Arazi et al. [38] reported that concurrent training might improve $\mathrm{VO}_{2}$ max among adult males. $\mathrm{VO}_{2} \max$ increase might be related to both parts of concurrent training. Endurance exercises increase mitochondria's number, size and volume, muscle myoglobin content, and oxidation enzyme activity that finally improve $\mathrm{VO}_{2} \max$. Resistance training increase $\mathrm{VO}_{2}$ max by increasing muscle capillary density, blood volume, and hemoglobin.

The concurrent resistance and endurance training increased muscle strength in a training group. Also, 
Kashani et al. [39] in comparison to two training methods found that resistance training and compound exercises play a significant role in increasing muscle strength of inactive males. Possible reasons of strength increase after resistance training were neural impulses number increase of movement units and anabolic hormone. Increasing strength after endurance training might have resulted from muscular neural consistency and improvement in muscular blood circulation distribution [40].

Also, current results showed that, concurrent resistance and endurance training group showed a significant decrease in comparison with a control group in lean mass, WHR, percentage of fat mass. Lack of bodyweight loss and BMI decrease following concurrent training of current research results are consistent with other research findings which might be due to endurance training nature. After all, such training not only decreases body fat percentage but also increases muscular mass [41].

One of the limitations of the present study was the lack of measurement of muscle mass. However, an increase in lean body mass is most likely due to an increase in muscle protein or muscle mass. Other limitations of the present study include the lack of control over the financial level, self-confidence, and lifestyle of the subjects and the lack of measurement of testosterone derivatives such as dehydroepiandrosterone.

\section{Conclusion}

Due to current research results, it might be suggested that performing a concurrent endurance-resistance training in men over 50 years of age lead to an increase in cardiorespiratory function, muscle strength, improvement in body composition and serum testosterone levels increase. Therefore, concurrent training (endurance-resistance) in men over 50 years of age may increase serum levels of testosterone to increase sexual function indices and subsequently improve their sexual behavior and. It might be a way to reduce the effects of aging and prevent the loss of their physical strength.

\section{Acknowledgment}

The authors would like to thank the head of Markazi province's oil industry's health center Mr. Masumi and arak's oil industry's special poly-technique laboratory Mr. Mohammadi who helped through this research plan.

\section{Funding}

This project was carried out as a research plan with the financial help of Arak State University (enacted 98/98 in sports Science College).

\section{Conflict of Interests}

The authors have no conflict of interest to declare.

\section{References}

1. Elbardisi H, Majzoub A, Daniel C, Al Ali F, Elesnawi M, Khalafalla K, et al. Endocrine contribution to the sexual dysfunction in patients with advanced chronic kidney disease and the role of hyperprolactinemia. Andrologia. 2021; e14135.

2. Lee LJ, Maguire TA, Maculaitis MC, Emir B, Li VW, Jeffress $M$, et al. Increasing access to erectile dysfunction treatment via pharmacies to improve healthcare provider visits and quality of life: Results from a prospective real-world observational study in the United Kingdom. Int J Clin Pract. 2021; 75(4): e13849.

3. Calzo JP, Austin SB, Charlton BM, Missmer SA, Kathrins $\mathrm{M}$, Gaskins AJ, Chavarro JE. Erectile dysfunction in a sample of sexually active young adult men from a us cohort: demographic, metabolic and mental health correlates. J Urol. 2021; 205(2): 539-44.

4. Polito MD, Papst R, Goessler K. Twelve weeks of resistance training performed with a different number of sets: Effects on maximal strength and resting blood pressure of individuals with hypertension. Clin Exp Hypertens. 2021; 43(2): 164-8.

5. Levy J. Impotence and its medical and psychosocial correlates: results of the Massachusetts Male Aging Study. Br J Diabetes Vasc Dis. 2002; 2(4): 278-80.

6. Moreira Jr ED, Lbo CFL, Diament A, Nicolosi A, Glasser DB. Incidence of erectile dysfunction in men 40 to 69 years old: results from a population-based cohort study in Brazil. Urology. 2003; 61(2): 431-6.

7. Chouten B, Bosch J, Bernsen R, Blanker M, Thomas $\mathrm{S}$, Bohnen A. Incidence rates of erectile dysfunction in the Dutch general population. Effects of definition, clinical relevance, and duration of follow-up in the Krimpen Study. Int J Impot Res. 2005; 17(1): 58-62.

8. Medina Polo J, Garcia Gomez B, Alonso Isa M, Romero Otero J. Clinical guidelines on erectile dysfunction surgery: EAU-AUA perspectives. Actas Urol Esp. 2020; 61(2): 431-6.

9. Adam A, McDowall J, Aigbodion SJ, Enyuma C, Buchanan S, Vachiat A, et al. Is the History of Erectile Dysfunction a Reliable Risk Factor for New-Onset Acute Myocardial Infarction? A Systematic Review and Meta-Analysis. Curr Urol. 2020; 14(3): 122-9.

10. Beiglbock H, Fellinger P, Ranzenberger Haider $T$, Itariu B, Prager G, Kautzky Willer A, et al. Pre operative Obesity Associated Hyperandrogenemia in Women and Hypogonadism in Men Have No Impact on Weight Loss Following Bariatric Surgery. Obes Surg. 2020; 30(10): 3947-54. 
11. Kim SH, Park JJ, Kim KH, Yang HJ, Kim DS, Lee $\mathrm{CH}$, et al. Efficacy of testosterone replacement therapy for treating metabolic disturbances in late-onset hypogonadism: a systematic review and meta-analysis. Int Urol Nephrol. 2021: 1-14.

12. Liang G, Song Y, Wang X, Li J, Shi H, Zhu Q, et al. Serum sex hormone-binding globulin is associated with symptomatic late-onset hypogonadism in aging rural males: a community-based study. Sex Health. 2021; 18(2): 156-61.

13. Kalyani, RR, M Corriere, L Ferrucci. Age-related and disease-related muscle loss: the effect of diabetes, obesity, and other diseases. Lancet Diabetes Endocrinol. 2014; 2(10): 819-29.

14. Parastesh M, Effect of concurrent training (enduranceresistance) on serum level of prostate specific antigen (PSA), cardiorespiratory endurance, muscular strength and body composition in men over 50 . Basic Clin Res J. 2020; 27(4): 11-8.

15. Gibson AL, Wagner D, Heyward V. Advanced Fitness Assessment and Exercise Prescription, 8E. Human kinetics; 2018 Sep 27.

16. Parastesh M. The Effect of Resistance Training on Serum Levels of Dehydroepiandrosterone, Estradiol and Erectile Dysfunction in Type 2 Diabetic Men. JNKUMS. 2020; 12(1): 1-8

17. Tang D, Li C, Peng DW, Zhang XS. Validity of premature ejaculation diagnostic tool and its association with International Index of Erectile Function-15 in Chinese men with evidence-based-defined premature ejaculation. Asian J Androl. 2018; 20(1): 19.

18. George JD, Vehrs PR, Allsen PE, Fellingham GW, Fisher $\mathrm{AG}$. $\mathrm{VO}_{2}$ max estimation from a submaximal 1 mile track jog for fit college-age individuals. Med Sci Sports Exerc. 1993; 25(3): 401-6.

19. Rissanen JA, Hakkinen A, Laukkanen J, Kraemer WJ, Häkkinen K. Acute neuromuscular and hormonal responses to different exercise loadings followed by a sauna. J Strength Cond Res. 2020; 34(2): 313-22.

20. Kraemer WJ, Loebel CC, Volek JS, Ratamess NA, Newton R.U, Wickham RB, et al. The effect of heavy resistance exercise on the circadian rhythm of salivary testosterone in men. Eur J Appl Physiol. 2001; 84(1): 13-8.

21. Gaeini AA. Effect of Complementary Saffron and Resistance Training on Serum Levels of Growth Hormone, Insulin-like Growth Factor-1 and Testosterone in Young Men. Iranian Endocrinol Metab. 2018; 20(4): 177-84.

22. Rashidi E, Hosseini Kakhak SAR, Askari R. The effect of 8 weeks resistance training with low load and high load on testosterone, insulin-like growth factor-1, insulin-like growth factor binding protein-3 levels, and functional adaptations in older women. Iranian $\mathrm{J}$ Ageing. 2019; 14(3): 356-67.
23. Jones TW, Howatson G, Russell M, French DN. Effects of strength and endurance exercise order on endocrine responses to concurrent training. Eur J Sport Sci. 2017; 17(3): 326-34.

24. Cadore EL, Izquierdo M, Dos Santos MG, Martins JB, Lhullier FLR, Pinto RS, et al. Hormonal responses to concurrent strength and endurance training with different exercise orders. J Strength Cond Res. 2012; 26(12): 3281-8.

25. Mirghani SJ, Alinejad, HA, Azarbayjani MA, Mazidi A, Mirghani SA. Influence of strength, endurance and concurrent training on the lipid profile and blood testosterone and cortisol response in young male wrestlers. Baltic J Health Phys Act. 2014; 6(1): 7.

26. Sheikholeslami VD, Siahkouhian M, Hakimi M, AliMohammadi M. The effect of concurrent training order on hormonal responses and body composition in obese men. Sci Sports. 2015; 30(6): 335-41.

27. Polito MD, Papst R, Goessler K. Twelve weeks of resistance training performed with different number of sets: Effects on maximal strength and resting blood pressure of individuals with hypertension. Clin Exp Hypertens. 2021; 43(2): 164-8.

28. Sokoloff NC, Misra M, Ackerman KE. Exercise training and the hypothalamic-pituitary-gonadal axis in men and women. Sports Endocrinol. 2016; 47: 27-43.

29. Shirvani H, Taheri Chadorneshin H, Kimiagar F. The effect of intense endurance exercise training and consumption of cinnamon powder on sex hormones in trained male cyclists. J Mil Med. 2017; 19(3): 245-52.

30. Roberts BM, Nuckols G, Krieger JW. Sex differences in resistance training: a systematic review and metaanalysis. J Strength Cond Res. 2020; 34(5): 1448-60.

31. Porcaro AB, Amigoni N, Tafuri A, Rizzetto R, Shakir $\mathrm{A}$, Tiso L, et al. Endogenous testosterone as a predictor of prostate growing disorders in the aging male. Int Urol Nephrol. 2021; 53(5): 843-54.

32. Træen B, Carvalheira A, Kvalem IL, Stulhofer A, Janssen E, Graham CA, Hald GM, Enzlin P. Sexuality in older adults $(65+)$ An overview of the recent literature, part 2: Body image and sexual satisfaction. Int J Sexual Health. 2017; 29(1): 11-21.

33. Kumagai H, Myoenzono K, Yoshikawa T, Tsujimoto T, Shimomura K, Maeda S. Regular aerobic exercise improves sexual function assessed by the Aging Males' Symptoms questionnaire in adult men. Aging Male. 2020; 23(5): 1194-201.

34. Eidelberg A, Cho A, Chughtai B. Effects of exercise on benign prostatic hyperplasia, lower urinary tract symptoms, and erectile dysfunction. In: Chughtai B, editor. Molecular Mechanisms of Nutritional Interventions and Supplements for the Management of Sexual Dysfunction and Benign Prostatic Hyperplasia. Elsevier. 2021. p. 189-212. 
35. Mahdian S, Bakhtiyari A, Eskandari M. Independent and interactive effect of Tribulus terrestris supplementation and resistance training on sexual and erectile function in obese men with type 2 diabetes. Iranian $\mathrm{J}$ Diabetes Metabol. 2019; 18(6): 322-33.

36. Garcia Pinillos F, Laredo Aguilera JA, Munoz Jimenez M, Latorre Roman PA. Effects of 12 week concurrent high-intensity interval strength and endurance training program on physical performance in healthy older people. J Strength Cond Res. 2019; 33(5): 1445-52.

37. Asghari Rakabdarkolaee M, Barari A, Abdi A, Hasrak K. The Effect of Eight-Week Concurrent Training on Aerobic Capacity and Serum Level of P53 Tumor Suppressor Protein in Prostate Cancer Patients: A Clinical Trial. J Rafsanjan Univ Med Sci. 2018; 17(8): $731-44$.

38. Arazi H, Jorbonian A, Asghari E. Comparison of concurrent (resistance-aerobic) and aerobic training on $\mathrm{VO}_{2}$ max lipid profile, blood glucose and blood pressure in middle-aged men at risk for cardiovascular disease. SSU J. 2013; 20(5): 627-38.

39. Kashiani AB, Geok SK, Soh KL, Ong SL, Kittichottipanich B. Comparison between two methods of variable resistance training on body composition, muscular strength and functional capacity among untrained males. Malaysian J Mov Health Exerc. 2020; 9(1): 45-66.

40. Sabag A, Najafi A, Michael S, Esgin T, Halaki M, Hackett D. The compatibility of concurrent high intensity interval training and resistance training for muscular strength and hypertrophy: a systematic review and meta-analysis. J Sports Sciences. 2018; 36(21): 2472-83.

41. Chew ST, Kayambu G, Lew CCH, Ng TP, Ong F, Tan J, et al. Singapore multidisciplinary consensus recommendations on muscle health in older adults: assessment and multimodal targeted intervention across the continuum of care. BMC Geriatrics. 2021; 21(1): $1-14$. 